\title{
Atmospheric Plasma Deposition of Diamond-like Carbon Coatings
}

\author{
Angela M. Ladwig ab, ${ }^{\text {a, }}$ Ronald D. Koch ${ }^{\text {a }}$, Edward G. Wenski ${ }^{\text {a }}$, and Robert F. Hicks ${ }^{\text {b }}$ \\ a National Nuclear Security Administration’s Kansas City Plant, Kansas City, Missouri, \\ United States \\ b Department of Chemical Engineering, University of California, Los Angeles, \\ California, United States
}

\section{Introduction}

There is great demand for thin functional coatings in the semiconductor, optics, electronics, medical, automotive and aerospace industries [1-13]. As fabricated components become smaller and more complex, the properties of the materials' surface take on greater importance. Thin coatings play a key role in tailoring surfaces to give them the desired hardness, wear resistance, chemical inertness, and electrical characteristics.

Diamond-like carbon (DLC) coatings possess an array of desirable properties, including outstanding abrasion and wear resistance, chemical inertness, hardness, a low coefficient of friction and exceptionally high dielectric strength [14-22]. Diamond-like carbon is considered to be an amorphous material, containing a mixture of $\mathrm{sp}^{2}$ and $\mathrm{sp}^{3}$ bonded carbon. Based on the percentage of $\mathrm{sp}^{3}$ carbon and the hydrogen content, four different types of DLC coatings have been identified: tetrahedral carbon (ta-C), hydrogenated amorphous carbon (a-C:H) hard, a-C:H soft, and hydrogenated tetrahedral carbon (ta-C:H) [20,24,25]. Possessing the highest hardness of $80 \mathrm{GPa}$, ta-C possesses an $\mathrm{sp}^{3}$ carbon content of 80 to $88 \mathrm{u} \%$, and no appreciable hydrogen content whereas a-C:H 
soft possesses a hardness of less than $10 \mathrm{GPa}$, contains an $\mathrm{sp}^{3}$ carbon content of $60 \%$ and a hydrogen content between 30 to $50 \%$.

Methods used to deposit DLC coatings include ion beam deposition, cathodic arc spray, pulsed laser ablation, argon ion sputtering, and plasma-enhanced chemical vapor deposition [73-83]. Researchers contend that several advantages exist when depositing DLC coatings in a low-pressure environment. For example, ion beam processes are widely utilized since the ion bombardment is thought to promote denser $\mathrm{sp}^{3}$-bonded carbon networks. Other processes, such as sputtering, are better suited for coating large parts $[29,30,44]$. However, the deposition of DLC in a vacuum system has several disadvantages, including high equipment cost and restrictions on the size and shape of material that may be treated.

The deposition of DLC at atmospheric pressure has been demonstrated by several researchers. Izake, et al [53] and Novikov and Dymont [54] have demonstrated an electrochemical process that is carried out with organic compounds such as methanol and acetylene dissolved in ammonia. This process requires that the substrates be immersed in the liquid [53-54]. The atmospheric pressure deposition of DLC was also demonstrated by Kulik, et al. utilizing a plasma torch. However, this process requires operating temperatures in excess of $800{ }^{\circ} \mathrm{C}$ [55].

In this report, we investigate the deposition of diamond-like carbon films using a low temperature, atmospheric pressure plasma-enhanced chemical vapor deposition (PECVD) process. The films were characterized by solid-state carbon-13 nuclear magnetic resonance $\left({ }^{13} \mathrm{C} \mathrm{NMR}\right)$ and found to have a ratio of $\mathrm{sp}^{2}$ to $\mathrm{sp}^{3}$ carbon of 43 to 
57\%. The films were also tested for adhesion, coefficient of friction, and dielectric strength.

\section{Experimental Methods}

A schematic of the plasma deposition system is shown in Figure 3.1. It consisted of the following components: an RF VII, Inc. $1000 \mathrm{~W}$ RF power generator at 27.12 MHz, an RF VII, Inc. auto-tuning matching network, 3 mass flow controllers, an evacuable chamber equipped with a resistive coil heater, and a downstream plasma source designed by Surfx Technologies, LLC. The chamber featured a removable lid, which the plasma source was welded onto, as well as a glass viewport. Ultra-high purity helium and acetylene (Scott Specialty, purity 99.6\%) were fed to the plasma source using nylon tubing. Stainless steel tubing was utilized for hydrogen transport as well as for the transport of the gas mixture from the controller to the plasma source. An additional helium line was added to purge the acetylene line if needed. A flash arrestor was placed on the acetylene line to prevent flashback, and flammable gas sensors were located by the gas cylinders and chamber lid. A third sensor was placed inside the control box and if triggered, would automatically shutdown the system. 


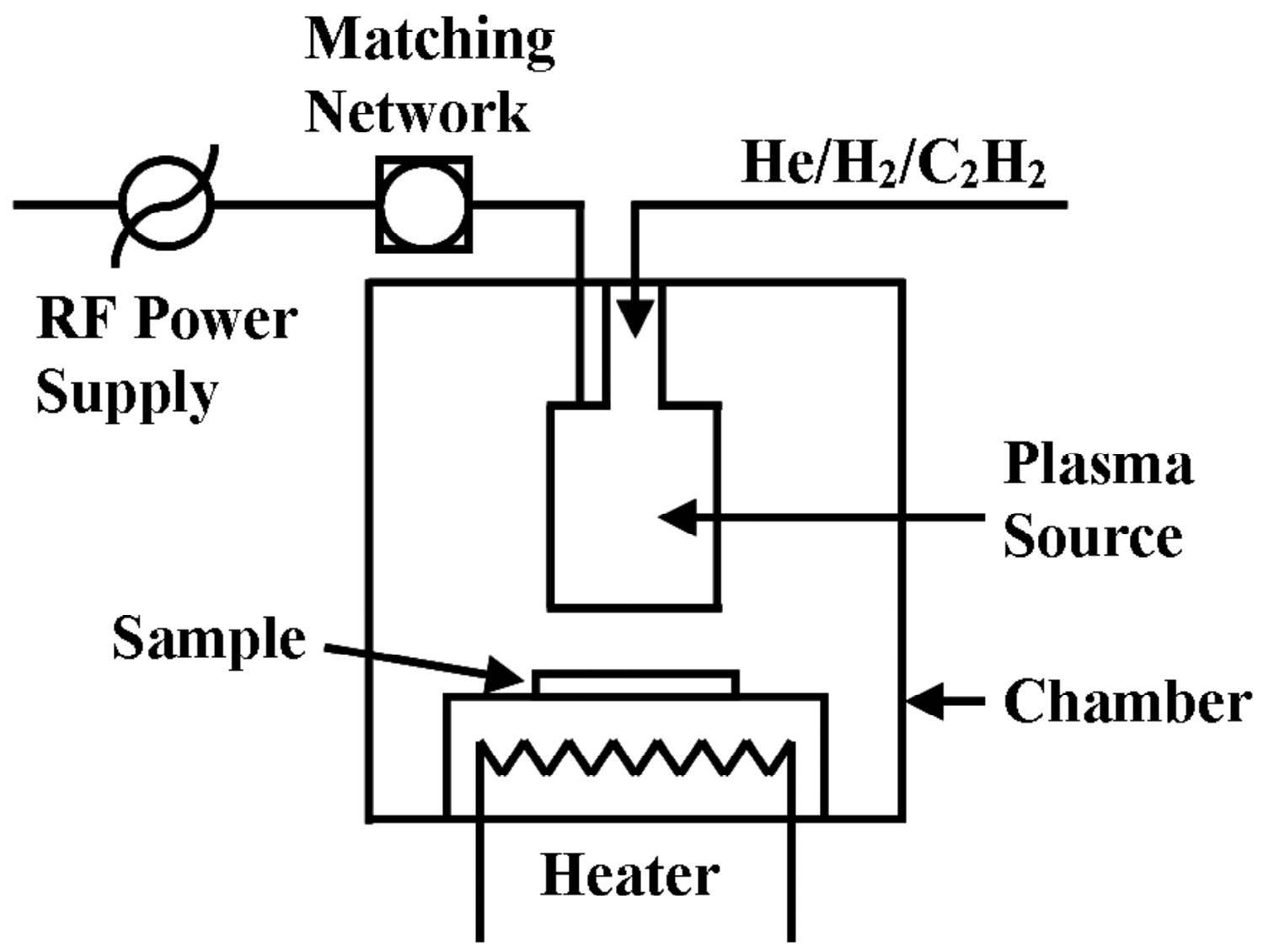


Figure 3.1 Flow schematic of DLC deposition process.

The coatings were deposited on two types of substrates: a p-type Si (100) wafer and a 304L stainless steel disk, 1.12” in diameter. The substrate was placed in the chamber with the plasma source mounted directly above it. The glass viewport was then sealed onto the chamber. Finally, the chamber was evacuated to approximately 50 Torr and backfilled with helium to 800 Torr.

The deposition procedure was as follows: the resistive coil heater was turned on and after the substrate reached the desired temperature, helium at $30.0 \mathrm{~L} / \mathrm{min}$ was introduced through the plasma source. Radio frequency power was then applied at 120 W. Next, hydrogen was introduced with a starting flow rate of $0.05 \mathrm{~L} / \mathrm{min}$. The RF power and hydrogen flow rate were simultaneously increased to a final value of $160 \mathrm{~W}$ and $0.50 \mathrm{~L} / \mathrm{min}$. Once the plasma stabilized, the acetylene was introduced at $0.01 \mathrm{~L} / \mathrm{min}$ and slowly increased to 0.05 or $0.10 \mathrm{~L} / \mathrm{min}$. The deposition time was varied between 5 and 25 min. After this period, acetylene and hydrogen flows, RF power and heater were turned off. Next, the chamber was evacuated to 50 Torr and backfilled with helium. Once atmospheric pressure was reached inside the chamber, the glass viewport was 
removed and the substrate was retrieved. Lastly, the helium flow was halted.

For mechanical testing, the silicon and stainless steel substrate were cleaned with an oxygen plasma prior to DLC deposition. The oxygen plasma was formed at an RF power of $250 \mathrm{~W}$ with $30.0 \mathrm{~L} / \mathrm{min}$ of helium and $0.3 \mathrm{~L} / \mathrm{min}$ of $\mathrm{O}_{2}$.

The carbon films were analyzed for nuclear magnetic resonance (NMR) data with a Bruker DSX 300 solid-state NMR spectrometer with operating frequencies of 300.13 $\mathrm{MHz}$ and $75.14 \mathrm{MHz}$ for ${ }^{1} \mathrm{H}$ and ${ }^{13} \mathrm{C}$, respectively. The ${ }^{13} \mathrm{C}$ cross-polarization/magicangle spinning (CP/MAS) spectra were obtained with a standard Bruker MAS probe using $4 \mathrm{~mm}$ (outside diameter) zirconium oxide $\left(\mathrm{ZrO}_{2}\right)$ rotors with Kel-F caps [56]. For maximum sensitivity, the ten-milligram samples scrapped from Si wafers were confined to the middle of the rotor (in order to be in the center of the radio frequency coil of the probe) by placing sodium chloride above and below the sample. Anisotropic interactions, such as chemical shift anisotropy, were minimized by magic-angle spinning. Potassium bromide ( $\mathrm{KBr}$ ) was used to adjust the magic angle with the upfield methine resonance of adamantane at $29.46 \mathrm{ppm}$ serving as the external chemical shift reference.

To reduce experimental time as well as enhance the sensitivity, cross-polarization from the abundant ${ }^{1} \mathrm{H}$ nuclei to the dilute ${ }^{13} \mathrm{C}$ nuclei was utilized. The recycle delay between scans in the cross-polarization experiment depends on the spin-lattice relaxation time of the protons. As ${ }^{1} \mathrm{H}$ nuclei possess significantly faster relaxation times than ${ }^{13} \mathrm{C}$ nuclei, data acquisition time is reduced in comparison to direct observation of the ${ }^{13} \mathrm{C}$ signal. All experiments were performed at ambient temperature. A $3.8 \mu \mathrm{s} \pi / 2$ pulse length was used with a contact time of $1.5 \mathrm{~ms}$. The recycle delay was $1.0 \mathrm{~s}$ with 75,000 
as the average number of scans acquired. By using a magic-angle spinning frequency of $10 \mathrm{kHz}$, it was possible to identify and reduce the intensities of spinning side bands [5759].

The percentage of carbon hybridization was calculated by deconvoluting the $\mathrm{sp}^{2}$ and $\mathrm{sp}^{3}$ resonance, found in the NMR spectrum at approximately 140 and $40 \mathrm{ppm}$, respectively [60-65]. The method fitted the observed resonances with 50\% Gaussian and $50 \%$ Lorentzian lineshapes. As a reference check, a solid-state ${ }^{13} \mathrm{C}$ NMR spectrum was acquire from diamond powder. A sharp resonance with a chemical shift at $34.9 \mathrm{ppm}$ was observed in agreement with the literature value of $36.0 \mathrm{ppm}$ [60].

Thickness measurements of the diamond-like carbon films on the silicon wafers were obtained using a Dektak 7 profilometer. To obtain a step height measurement, the samples were masked and then mechanically scratched. This data also lead to the determination of the deposition rate. These measurements could not be made with sufficient accuracy on the stainless steel coupons due to their high surface roughness.

The adhesion of the DLC coatings to the stainless steel and Si wafer was determined using a stud pull test [64]. The test device was a Romulus III from Quad Group Inc. A metal stud, 0.1” diameter, was affixed to the coating surface using epoxy glue. The stud was then pulled perpendicular to the substrate at a rate of $6 \mathrm{lb} / \mathrm{s}$. Adhesive strength is defined as the amount of pressure required to remove the stud from the substrate. After the pull test, the fractured surface was examined by scanning electron microscopy (SEM) using a Leo 1455VP. No conducting coating was applied. All images were obtained at $25 \mathrm{x}$ with an accelerating voltage of $25 \mathrm{kV}$ and a working 
distance of $8 \mathrm{~mm}$. Quad-backscattering detection was employed.

Pin on disk testing, per ASTM G99, was performed to obtain the coefficient of friction. A $3.75 \mathrm{~mm}$ radius wear track was created at a speed of $2.8 \mathrm{~cm} / \mathrm{s}$. Coefficient of friction values were calculated by dividing the normal load $(1.0 \mathrm{~N})$ by the force obtained after 100 cycles.

Several attempts were made to obtain the dielectric strength and breakdown voltage of the coatings. These measurements were performed on a HyPot III 3665 tester from Associated Research as outlined by ASTM D3755. However, these results were inconsistent, yielding dielectric strengths that ranged from 0 to $350 \mathrm{~V}$ DC from one sample to the next.

\subsection{Results}

\section{Carbon Bonding}

A solid-state ${ }^{13} \mathrm{C}$ NMR spectrum of the carbon film obtained from several samples is displayed in Figure 3.2. The process conditions were $160 \mathrm{~W}$ RF power, $155{ }^{\circ} \mathrm{C}$ substrate temperature, source-to-substrate distance of $8 \mathrm{~mm}, 0.10 \mathrm{~L} / \mathrm{min}$ acetylene flow, $0.50 \mathrm{~L} / \mathrm{min}$ hydrogen flow, and $30.0 \mathrm{~L} / \mathrm{min}$ helium flow. As seen in the Figure 3.2, two main resonance bands are observed, centered at approximately 128 and 38 ppm. These bands are due to $\mathrm{sp}^{2}$ and $\mathrm{sp}^{3}$ carbon bonding, respectively, and demonstrate the successful deposition of a diamond-like carbon film. The $\mathrm{sp}^{2}$ band was deconvoluted into two peaks, while the $\mathrm{sp}^{3}$ band was deconvoluted into three peaks. Table 3.1 lists the position of each deconvoluted peak as a fraction of the total band area. The $\mathrm{sp}^{3}$ peaks centered about 80 and $15 \mathrm{ppm}$ are due to spinning side bands and were not included in the $\mathrm{sp}^{2} / \mathrm{sp}^{3}$ 
ratio. Based on the area under the bands, the $\mathrm{sp}^{2} / \mathrm{sp}^{3}$ ratio was estimated to be $43 \% / 57 \%$. In summary, diamond-like carbon coatings have been deposited using a atmospheric pressure plasma fed with acetylene, hydrogen and helium at a substrate temperature of $155^{\circ} \mathrm{C}$. 


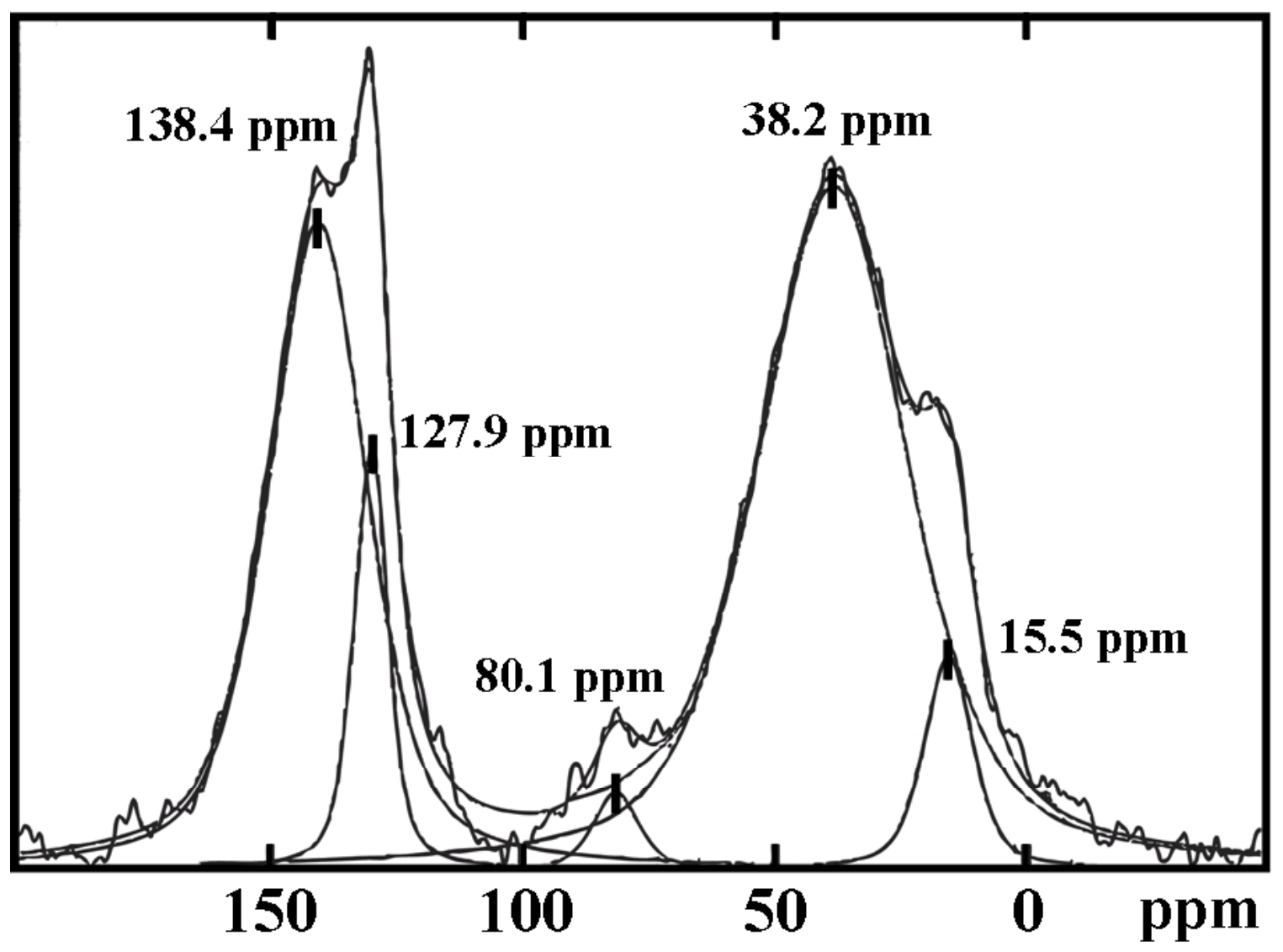


Figure 3.2 Solid-state ${ }^{13} \mathrm{C}$ NMR spectrum of an atmospheric pressure deposited DLC coating.

Table 3.1 Position and area of $\mathrm{sp}^{2}$ and $\mathrm{sp}^{3}$ carbon peaks.

\begin{tabular}{cccc}
\hline \hline Carbon type & Peak No. & Position (ppm) & Fraction of total area \\
\hline $\mathrm{sp}^{2}$ & 1 & 138.4 & 0.33 \\
$\mathrm{sp}^{2}$ & 2 & 127.9 & 0.08 \\
$\mathrm{sp}^{3}$ & 3 & 80.1 & 0.05 \\
$\mathrm{sp}^{3}$ & 4 & 38.2 & 0.52 \\
$\mathrm{sp}^{3}$ & 5 & 15.5 & 0.02 \\
\hline \hline
\end{tabular}




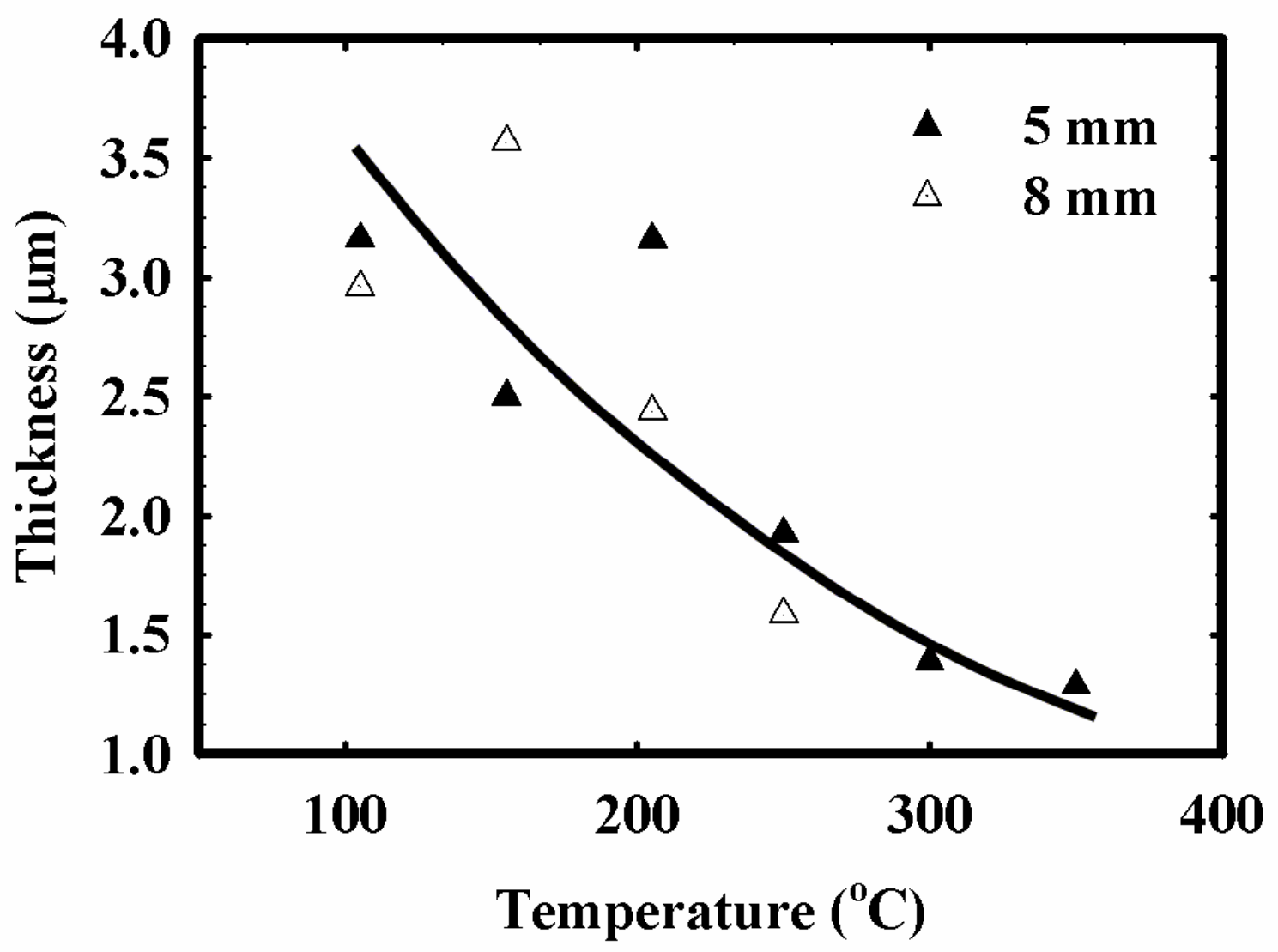


Figure 3.3 Thickness of DLC coatings as a function of deposition temperature with $0.10 \mathrm{~L} / \mathrm{min}$ of $\mathrm{C}_{2} \mathrm{H}_{2}$ and a source-to-substrate distance of $5 \mathrm{~mm}$ and $8 \mathrm{~mm}$. 


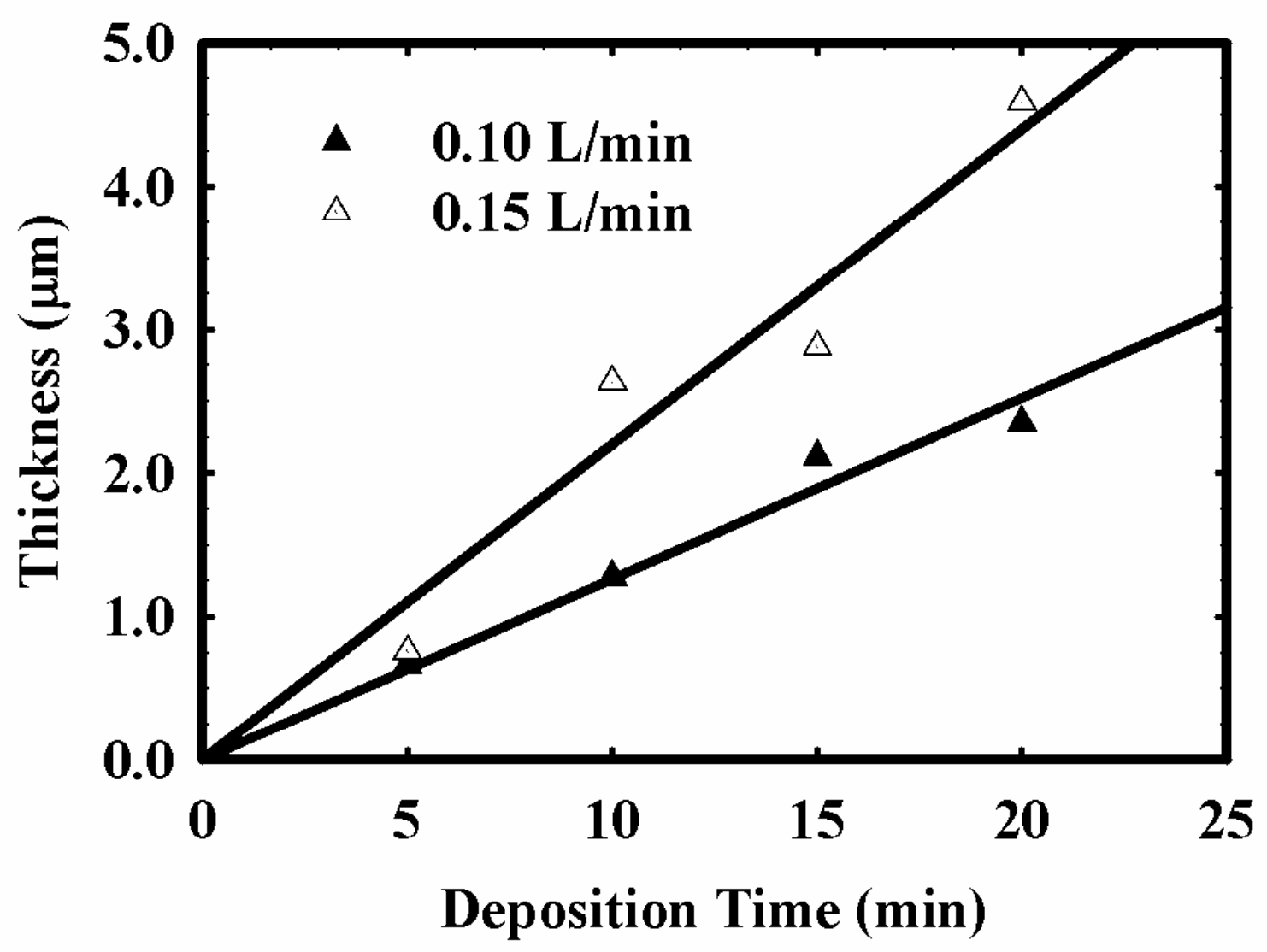


Figure 3.4 Thickness of DLC coatings as a function of deposition time at two $\mathrm{C}_{2} \mathrm{H}_{2}$ flow rates, a substrate temperature of $200{ }^{\circ} \mathrm{C}$, and a source-to-substrate distance of $10 \mathrm{~mm}$.

Effects of Process Conditions

Shown in Figure 3.3 is the effect of temperature on the DLC coating thickness for two different source-to-sample distances. Deposition was carried out for 25 minutes at $160 \mathrm{~W}$ RF power, $0.10 \mathrm{~L} / \mathrm{min}$ acetylene, $0.5 \mathrm{~L} / \mathrm{min}$ hydrogen, $30.0 \mathrm{~L} / \mathrm{min}$ helium and 5 and $8 \mathrm{~mm}$ source-to-substrate distances. One sees that the film thickness drops rapidly as the substrate is increased from 155 to $350{ }^{\circ} \mathrm{C}$. At $105{ }^{\circ} \mathrm{C}$, the thickness is approximately the same as that observed at 155 and $205{ }^{\circ} \mathrm{C}$. To within the experimental error, there is no difference in deposition rate for the 5 and $8 \mathrm{~mm}$ source-to-substrate distances. Is it noted that a loosely bound amorphous carbon by-product is observed at substrate temperatures of 105 and $155{ }^{\circ} \mathrm{C}$ for 8 and $5 \mathrm{~mm}$ source-to-substrate distances, respectively.

The dependence of the film thickness on deposition time at the different acetylene flow rates is shown in Figure 3.4. The process conditions are the same as reported earlier, except that the substrate temperature is $200{ }^{\circ} \mathrm{C}$ and the source-to-substrate distance is $10 \mathrm{~mm}$. The thickness varies linearly with time with the lines extrapolating 
back to the origin. This indicates that there is no induction period for the onset of DLC deposition. The film growth rate is obtained from the slope of the lines, which equals $0.13 \pm 0.04 \mathrm{~mm} / \mathrm{min}$ for $0.10 \mathrm{~L} / \mathrm{min}$ acetylene flow and $0.22 \pm 0.07 \mathrm{~mm} / \mathrm{min}$ for $0.15 \mathrm{~L} / \mathrm{min}$ acetylene flow. At a deposition time of 10 min or greater, coatings processed with 0.15 $\mathrm{L} /$ min acetylene flow exhibited average thickness levels as much as $52 \%$ higher than coatings processed at $0.10 \mathrm{~L} / \mathrm{min}$ acetylene flow, indicating that the deposition rate is positive order in acetylene flow rate.

\section{Adhesion, Wear and Dielectric Strength}

The adhesive strength of the DLC coatings, measured by a stud pull test, are shown in Table 3.2. For Samples A and B, a stainless steel substrate was used, whereas for sample C a silicon substrate was used. When the substrates were not plasma treated, the adhesion ranged from 3650 to 5370 psi. On the other hand, the oxygen plasma treatment of the substrates had an adverse effect, decreasing the strengths 40 to $90 \%$. After failure, the surfaces of the steel coupons were examined with the SEM, and these results are shown in Figure 3.5. The SEM images reveal small amounts of unremoved coatings around the edges of the circular test region and very thin layers of coating with the center region. No removed coating was observed for DLC deposited on the silicon substrates.

Coefficient of friction values for DLC deposited on 304L stainless steel coupons were found to be $0.24 \pm 0.02$, per ASTM G99. It was found that the oxygen plasma treatment prior to deposition had no impact on the coefficient of friction values. 
Dielectric strength data was collected from coatings deposited on SS coupons. The results obtained were inconsistent as one area of the coating would exhibit dielectric strengths greater than $300 \mathrm{~V}$ and other area would exhibit zero strength, indicating that a short was immediately detected by the test device.

Table 3.2 Adhesion data for DLC coatings.

\begin{tabular}{ccc}
\hline \hline Sample & \multicolumn{2}{c}{ Adhesion (psi) } \\
\cline { 2 - 3 } & No treatment & $\mathrm{O}_{2}$ plasma clean \\
\hline $\mathrm{A}$ & 3650 & 2300 \\
$\mathrm{~B}$ & 5370 & 3820 \\
$\mathrm{C}$ & 4550 & 520 \\
\hline \hline
\end{tabular}




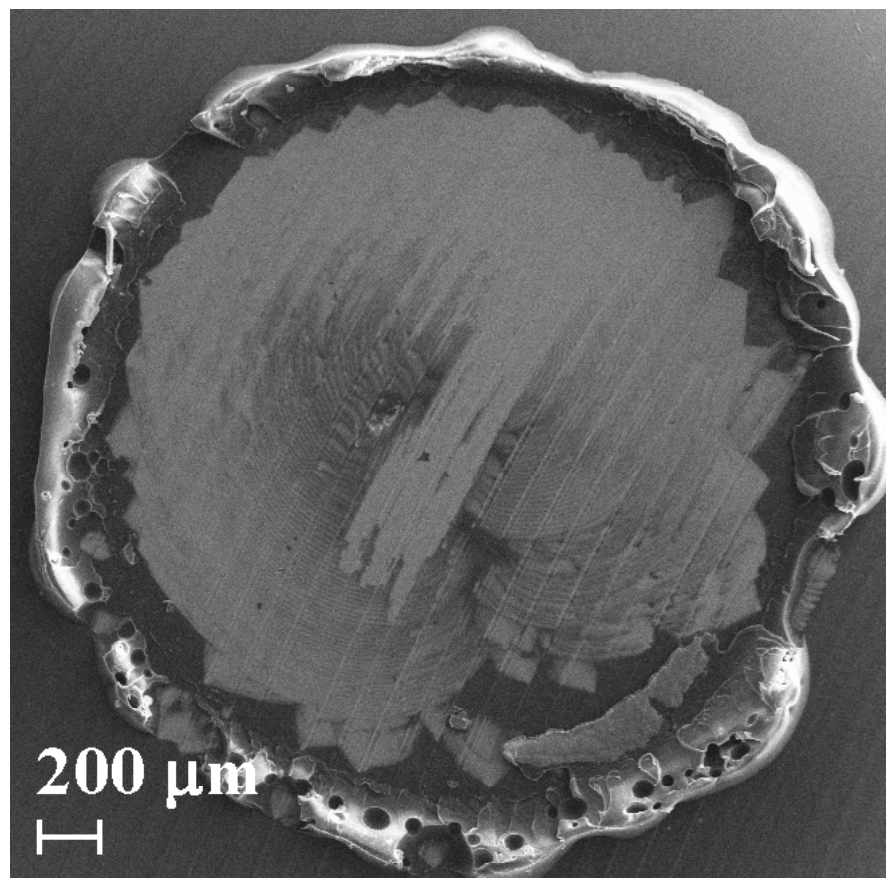




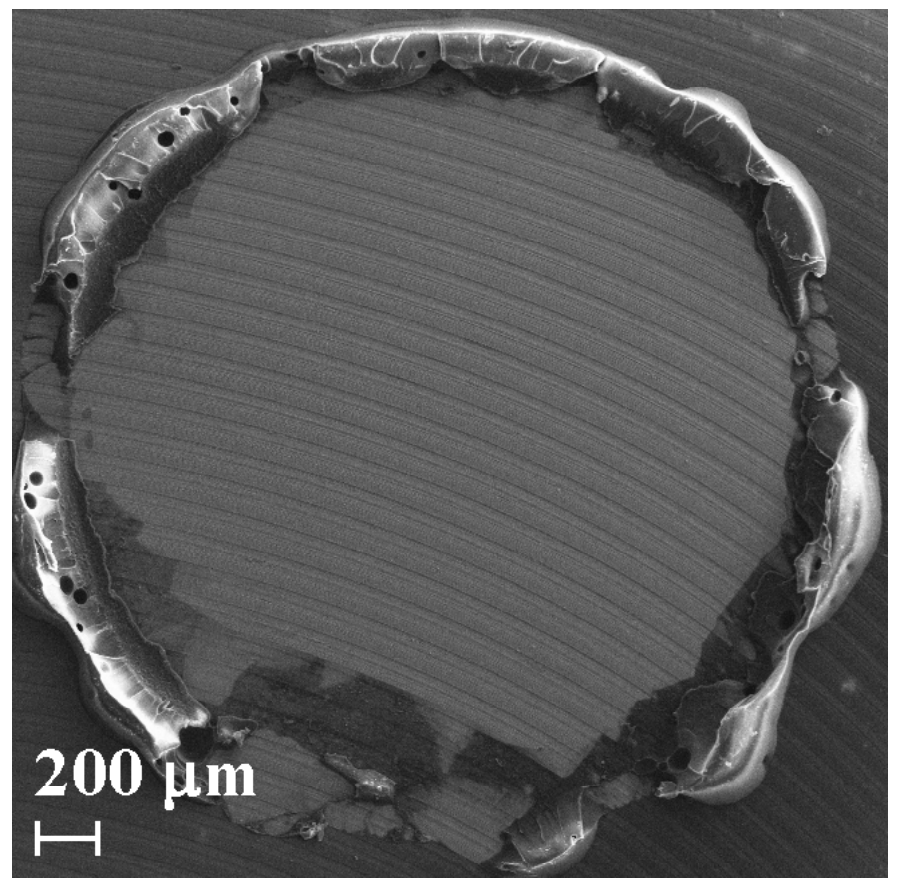

Figure 3.5 Scanning electron micrographs of DLC coatings after the adhesion test: (a) without; and (b) with plasma treatment prior to deposition. 


\subsection{Discussion}

It has been found that diamond-like carbon can be deposited at low-temperature and atmospheric pressure using a downstream acetylene, hydrogen and helium plasma. As shown in Figure 3.2, solid-state ${ }^{13} \mathrm{C}$ NMR resonance peaks are observed at approximately $128 \mathrm{ppm}$ due to $\mathrm{sp}^{2}$ carbon, and at approximately $38 \mathrm{ppm}$ due to $\mathrm{sp}^{3}$ carbon. These chemical shifts are in good agreement with the values reported for diamond-like carbon deposited in vacuum processes [60-64]. For example, Merwin et al. [60] reports chemical shifts of 120.0 and $34.5 \mathrm{ppm}$ for $\mathrm{sp}^{2}$ and $\mathrm{sp}^{3}$ carbon, respectively, whereas Bustillo et al [62] reports chemical shifts of 140.0 and $40.0 \mathrm{ppm}$ for $\mathrm{sp}^{2}$ and $\mathrm{sp}^{3}$ carbon. The broadness of the NMR resonance bands reflects the effect of dispersion in the observed chemical shifts, i.e. different types of $\mathrm{sp}^{2}$ and $\mathrm{sp}^{3}$ carbon bonding in the films [38,63]. The peaks at 138.4 and $127.1 \mathrm{ppm}$ may be associated to unsaturated $\mathrm{CH}$ and $\mathrm{CH}_{2}$ groups, respectively. On the other hand, the broad peak at 38.2 may be assigned to saturated carbon atoms with 1,2 or 3 hydrogen atoms attached.

The ratio of $\mathrm{sp}^{2}$ to $\mathrm{sp}^{3}$ carbon bonding was determined to be 43:57. Based on the four classifications of DLC coatings, the material produced in this study may be designated as a-C:H soft. The hardness of a-C:H soft coatings is considered to be $<10$ GPa with a hydrogen percentage of 40 to $50 \%$ [24].

The results shown in Figure 3.3 and 3.4 reveal that the rate of DLC deposition decreased rapidly with substrate temperature from 150 to $350{ }^{\circ} \mathrm{C}$, but increased with the partial pressure of acetylene. The optimal temperature for growth is around $200{ }^{\circ} \mathrm{C}$, since this yields a high rate while at the same time avoiding the formation of a loosely bound 
carbon deposit. At the higher acetylene flow of $0.15 \mathrm{~L} / \mathrm{min}$, a deposition rate of 0.22 $\mu \mathrm{m} / \mathrm{min}$ is achieved. This may be compared to vacuum processes where rates have been reported as low as $10^{-3} \mu \mathrm{m} / \mathrm{min}$ to as high as $0.6 \mu \mathrm{m} / \mathrm{min}$, depending on the method utilized [65-66].

The coefficient of friction for the DLC obtained in this study was $0.24+0.02$. Previous studies report coefficient of friction values for vacuum deposited coatings to be within the range of $0.05-1.00[1,64,67-70]$. For uncoated stainless steel, the coefficient of friction is 0.55 [71].

The work presented above is the first successful demonstration of diamond-like carbon deposition using a downstream, low-temperature atmospheric pressure plasma source. Additional work is needed to further improve the process and enhance the properties of the DLC coatings.

\subsection{Conclusions}

The deposition of diamond-like carbon using a low-temperature, atmospheric pressure plasma process is reported for the first time. Using solid-state ${ }^{13} \mathrm{C}$ NMR spectroscopy, the coatings were found to possess a ratio of 43 to $57 \% \mathrm{sp}^{2}$ to $\mathrm{sp}^{3}$ carbon. A deposition rate of $0.22 \mu \mathrm{m} / \mathrm{min}$ was observed at $160 \mathrm{~W}$ RF power, $200{ }^{\circ} \mathrm{C}$ substrate temperature, $10 \mathrm{~mm}$ source-to-substrate distance, $0.15 \mathrm{~L} / \mathrm{min}$ acetylene flow, $0.50 \mathrm{~L} / \mathrm{min}$ hydrogen and $30.0 \mathrm{~L} / \mathrm{min}$ helium. The DLC coatings were found to reduce the coefficient of friction of stainless steel from 0.55 to $0.26+0.02$. Further work will be performed to enhance the functionality of the DLC coatings.

\subsection{Acknowledgements}


This research was supported by Plant Directed Research and Development funding from the Department of Energy's National Nuclear Security Administration's Kansas City Plant. The Bruker DSX 300 solid-state NMR spectrometer was supported by the National Science Foundation under equipment grant number DMR-9975975. 


\section{References}

1. A. Grill, Diamond Rel. Mater. 8428 (1999).

2. I.S. Forbes, J.I.B. Wilson, Thin Solid Films 420-421 508 (2002).

3. K.K. Chan, S.R.P. Silva, G.A.J. Amaratunga, Thin Solid Films 212232 (1992).

4. H. Fukui, J. Okida, N. Omori, H. Moriguchi, K. Tsuda, Surf. Coat. Technol. 18770 (2004).

5. L. Huang, K. Xu, J. Lu, B. Guelorget, H. Chen, Diamond Rel. Mater. 101448 (2001).

6. J.Y. Chen, L.P. Wang, K.Y. Fu, N. Huang, Y. Leng, Y.X. Leng, P. Yang, J. Wang, G.J. Wan, H. Sun, X.B. Tian, P.K. Chu, Surf. Coat. Technol. 156289 (2002).

7. J. Seth, S.V. Babu, V.G. Ralchenko, T.V. Kononenko, V.P. Ageev, V.E. Strelnitsky, Thin Solid Films 25492 (1995).

8. N. Savvides, J. Appl. Phys. 594133 (1986).

9. H. Yamashita, I. Amemiya, E. Nomura, K. Nakajima, H. Nozue, J. Vac. Sci. Technol. B 183237 (2000).

10. A.C. Ferrari, Surf. Coat. Technol. 180-181 190 (2004).

11. R. Wachter, A. Cordery, S. Proffitt, J.S. Foord, Diamond Rel. Mater. 7687 (1998).

12. N.V. Novikov, A.G. Gontar, S.I. Khandozhko, A.M. Kutsay, V.N. Tkach, V.Y. Gorokhov, G.M. Belitsky, A.V. Vasin, Diamond Rel. Mater. 9792 (2000).

13. S. Meskinis, V. Kopustinskas, K. Slapikas, A. Guobiene, R. Gudaitis, S. Tamulevicius, Mater. Sci. 11317 (2005).

14. H.O. Pierson, Handbook of Chemical Vapor Deposition, Noyes Publications, Norwich, NY, 1999.

15. A. Grill, B.S. Meyerson, in: H.E. Spear, J.P. Dismukes (Ed.), Synthetic Diamond: Emerging CVD Science and Technology, John Wiley \& Sons, New York, 1994.

16. E. Staryga, G.W. Bak, M. Dluzniewski, Vacuum 74325 (2004). 
17. J.W. Zou, K. Reichelt, K. Schmidt, B. Dischler, J. Appl. Phys. 653914 (1989).

18. M. Suzuki, T. Watanabe, A. Tanaka, Y. Koga, Diamond Rel. Mater. 122061 (2003).

19. J. Robertson, Mat. Sci. Engr. R 37129 (2002).

20. D.R. McKenzie, Rep. Prog. Phys. 591611 (1996).

21. A. Grill, Thin Solid Films 355-356 189 (1999).

22. J.W. Zou, K. Reichelt, K. Schmidt, B. Dischler, J. Appl. Phys. 653914 (1989).

23. P. Koidl, C. Wild, B. Dischler, J. Wagner, M. Ramsteiner, Mater. Sci. Forum 5241 (1990).

24. J.C. Angus, C.C. Hayman, Science 241913 (1988).

25. H. Zaidi, T.L. Huu, D. Paulmier, Diamond Rel. Mater., 3787 (1994).

26. D.L. Pappas, K.L. Saenger, J. Bruley, W. Krakow, J.J. Cuomo, T. Gu, R.W. Collins, J. Appl. Phys. 715675 (1992).

27. O. Takai, V. Anita, N. Saito, Surf. Coat. Technol. 2001106 (2005).

28. S.S. Choi, D.W. Kim, J.W. Joe, J.H. Moon, K.C. Park, J. Jang, Mat. Sci Engr. B 46 133 (1997).

29. D. Hess, K.F. Jensen, Microelectronics Processing: Chemical and Engineering Aspects, American Chemical Society, Washington, (1989).

30. L. Li, H. Zhang, Y. Zhang, P.K. Chu, X. Tian, L. Xia, X. Ma, Mat. Sci. Engr. B 94 95 (2002).

31. V. Palshin , E.I. Meletis, S. Ves, S. Logothetidis, Thin Solid Films 270165 (1995).

32. C. Ronning, Appl. Phys. A 7739 (2003).

33. E.C. Samano, G. Soto, A. Olivas, L. Cota, Appl. Surf. Sci. 2021 (2002).

34. R.R. Mimmagadda, J. Mater. Res. 5 (1990).

35. T. Sato, S. Furuno, S. Iguchi, and M. Hanabusa, Appl. Phys. A 45355 (1988).

36. A. Grill, IBM J. Res. Develop. 43 (1999). 
E.L. Izake, T. Paulmier, J.M. Bell, P.M. Fredericks, J. Mater. Chem. 15300 (2005).

37. V.P. Novikov, V.P. Dymont, Appl. Phys. Lett. 70200 (1997).

38. D. Liu, S. Yu, T. Ma, S.Z. Song, X. Yang, Jpn. J. Appl. Phys. 393359 (2000).

39. J. Schaefer, E.O. Stejskal, J. Am. Chem. Soc. 981031 (1976).

40. R.E. Taylor, Concepts Mag. Reson. A 2237 (2004).

41. G. Beamson, W.J. Brennan, N.J. Clayden, R.C.K. Jennings, J. Poly. Sci. B 311205 (1993).

42. A. Dilks, S. Kaplan, A. Van Laeken, J. Poly. Sci 192987 (1981).

43. L.H. Merwin, C.E. Johnson, W.A. Weimer, J. Mater. Res. 9631 (1994).

44. J. Braddock-Wilking, S.-H. Lin, B.J. Feldman, Phys. Rev. B 599745 (1999).

45. K.C. Bustillo, M.A. Petrich, J.A. Reimer, Chem. Mater. 2202 (1990).

46. S. Kaplan, F. Jansen, M. Machonkin, Appl. Phys. Lett. 47750 (1985).

47. A. Grill, B.S. Meyerson, V.V. Patel, IBM J. Res. Develop. 34849 (1990).

48. J.W. Zou, K. Reichelt, K. Schmidt, B. Dischler, J. Appl. Phys. 653914 (1989).

49. S. Kaplan, A. Dilks, Thin Solid Films 84419 (1981).

50. S. Sundararajan, B. Bhushan, Wear 225-229 678 (1999).

51. E.V. Anoikin, M.M. Yang, J.L. Chao, J.R. Elings, D.W. Brown, J. Vac. Sci. Technol. A 161741 (1998).

52. Y.X. Leng, J.Y. Chen, P. Yang, H. Sun, G.J. Wan, N. Huang, Surface Science 531 177 (2003).

53. D. Liu, G. Benstetter, E. Lodermeier, I. Akula, I. Dudarchyk, Y. Liu, T. Ma, Surf. Coat. Technol. 172194 (2003).

54. N. Ikenaga, K. Awazu, N. Sakudo, H. Yasui, T. Kawabata, Surf. Coat. Technol. 196 226 (2005). 
55. RA. Serway ${ }_{2}$ Physics for Scientists and Engineers, $4^{\text {th }}$ edition, Saunders College Publications, Philadelphia, 1996 